\title{
In Situ Biosynthesis of Natural Fruity Flavors in Whey and Whey Permeate during Fermentation Using Lipase
}

\author{
Maryam Shojaei Zinjanab ${ }^{1}$, Mohammad Taghi Golmakani ${ }^{2} *$, Mohammad Hadi Eskandari ${ }^{2}$, Mahmoud Aminlari $^{3}$ \\ 1- PhD Candidate in Food Science and Technology-Food Microbiology, Department of Food Science and Technology, School of Agriculture, Shiraz \\ University, Shiraz, Iran \\ 2- Associate Professor, Department of Food Science and Technology, School of Agriculture, Shiraz University, Shiraz, Iran \\ 3- Professor, Department of Biochemistry, School of Veterinary Medicine, Shiraz University, Shiraz, Iran
}

\section{A B S T R A C T}

Background and Objectives: Chemical synthesis and extraction of flavorings from natural sources include disadvantages. However, biotechnology is a preferred method for biosynthesis of flavorings. The objective of this study was to synthesize natural esters with fruity flavors in whey using lipase of Palatase in combination with ethanol fermentation.

Materials and Methods: Lactobacillus fermentum ATCC 14931, Lactobacillus reuteri DSM 17938, and Lactobacillus buchneri NCIMB 40788 were used as in situ ethanol producers. Ultra-high temperature (UHT) cream (30\% fat) was added to the fermentation media as a fat source, which was esterified with produced ethanol by Palatase. Viable cell counts and $\mathrm{pH}$ were monitored at 0,24 (Palatase addition), and $48 \mathrm{~h}$ (end of fermentation). Free fatty acids of up to 12 carbon chain and their ethyl esters were analyzed using gas chromatography/mass spectrometry.

Results: Palatase did not affect the viable cell counts of Lactobacillus reuteri and Lactobacillus buchneri, but increased the viable cell counts of Lactobacillus fermentum. Ethyl ester and free fatty acid levels of the samples increased after Palatase addition. Lactobacillus fermentum produced higher ester levels in ultrafiltration whey permeate whereas other lactobacilli produced higher ester levels in traditional whey. Lactobacillus buchneri included the lowest ester levels and Lactobacillus reuteri included the lowest free fatty acid levels between the lactobacilli. The ester levels of Lactobacillus reuteri samples were the highest in most cases. Free fatty acid levels were higher in traditional whey than ultrafiltration whey permeate.

Conclusions: This method can be recommended as an alternative to artificial flavorings with the advantage of labeling products as natural.

Keywords: Fermentation, Flavor ester, Lactobacillus, Lipase, Whey

\section{Introduction}

Flavor is one of the most important factors in the food industry since it affects product acceptance in the market (1). Although flavor compounds are naturally detected in foods, they are added to food products as flavor enhancers or improvers (2). Food flavorings are divided into three major categories of natural, nature-identical and artificial flavorings. Based on the consumer demands, production and use of natural flavors replace those of chemically synthesized flavors. Natural flavors are flavors that are produced from natural materials using extraction and biotechnological methods. Since extraction is expensive, biotechnology is the preferred method of producing these compounds. Microbial fermentation and enzyme use are two common biotechnological methods in flavor production. Naturally, efficiency of the enzymatic method is higher than that of fermentation method $(3,4)$. A wide range of chemical compounds such as esters can attribute to food flavors (5). Esters of short and medium chain fatty acids (SCFA and MCFA, respectively) and alcohols are used in food industries as flavor compounds with pleasant fruity flavors. However, esters of fatty acids (FA) with carbon chains longer than 12 cause undesirable soapy or tallowy tastes (6). Lipases are biocatalysts with the ability of producing esters via interesterification, alcoholysis and 
direct esterification of FAs with alcohols. Although, most lipases include catalytic activities in media with low water activity, a few lipases can produce esters in aqueous media (7). Of these lipases, a purified lipase from Rhizomucor miehei produced by the recombinant Aspergillus oryzae with the commercial name of Palatase 20000 L has been introduced for use in foods (8). Palatase specificity uses short chain fatty acids (SCFA) for esterifying and hence does not leave undesirable flavors (7). This food-grade enzyme has been used for ester productions in foods $(6,9$, 10).

One of the methods that have recently been developed to produce fruity flavors in foods includes in situ ester production via enzymatic biosynthesis $(7,9-11)$. Alcohol is added manually in most in situ ester productions; however, researchers benefit microbial fermentation to eliminate alcohol handling which seems a better alternative. Liu et al. (2009) and Zhang et al. (2016) used spiked ethanol to produce flavor esters in dairy products $(10,11)$. However, combination of fermentation with lipase addition to produce fruity flavor in coconut creams has been carried out in a few studies using in situ produced ethanol. Triglycerides (TG) of coconut creams were esterified with produced ethanol using Palatase. Labeling food products as natural is an advantage of in situ ester production using the combined systems (9). The worldwide production of whey is estimated as nearly 120 million tons annually, which raises environmental concerns. Researchers try to transform whey into value-added products; however, large quantities of whey are still discarded into the environments of developing countries $(12,13)$. Heterofermentative lactic acid bacteria (LAB) include abilities to produce ethanol and esters, which are important factors in development of flavors $(14,15)$. However, their use as ethanol producers with Palatase in ester synthesis has not been reported yet. Lactobacillus is one of the important genera of LAB with homo and heterofermentative species (16). The major objective of this study was to assess in situ biosynthesis of natural ethyl esters with fruity flavors in traditional whey and ultrafilter (UF) whey permeate using lipase Palatase in combination with alcoholic fermentation. Three heterofermentative lactobacilli were used as ethanol producing cultures. The FAs, the other precursor of ester synthesis, were produced by adding milk fat (cream) to the whey media. Enumeration of the bacterial viable cell and $\mathrm{pH}$ measurement were carried out to monitor the fermentation process. Since sensory analysis normally depends on individuals, a further precise method, gas chromatography/mass spectrometry (GC/MS), was used to analyze the produced esters as well as FFAs.

\section{Materials and Methods}

\section{Materials and microorganisms}

In general, de Man Rogosa Sharpe (MRS) broth, MRS agar, bacteriological peptone and hexane were purchased from Merck, Darmstadt, Germany. Lipase of Palatase 20000 L (Novozymes, Bagsværd, Denmark) and Chymosin CHY-MAX (Chr. Hansen A/S, Hørsholm, Denmark) were purchased with high grades. Lactobacillus fermentum ATCC 14931 (PTCC 1744) was purchased from Persian Type Culture Collection, Tehran, Iran, as pure culture in freeze-dried form. Lactobacillus reuteri DSM 17938 and Lactobacillus buchneri NCIMB 40788 were respectively isolated from Biogia and Lalsil fresh in Food Microbiology Lab of the University of Shiraz, Shiraz, Iran. Permeate powder of UF cheese whey $(95 \%$, w/w dry matter), pasteurized milk (1.5\% fat) and ultra-high temperature (UHT) cream (30\% fat) were purchased from Pegah Fars Dairy Industry, Shiraz, Iran.

\section{Preparation of fermentation media}

The UF whey permeate powder was dissolved in distilled water (DW) to prepare UF whey permeate solution with $5 \%$ dry matter. Cheese curd was prepared by heating pasteurized milk to $45{ }^{\circ} \mathrm{C}$ and adding $0.4 \%$ of chymosin. Cheese curd was filtered to prepare traditional whey. The UF whey permeate and traditional whey were sterilized using autoclave. Moreover, UHT cream was added to two fermentation media at $10 \%$ to provide FA source for ester production.

\section{Preparation of microbial inocula}

Lactobacillus cultures were propagated in MRS broth at $37{ }^{\circ} \mathrm{C}$ for $48 \mathrm{~h}$ and stored at $-80{ }^{\circ} \mathrm{C}$ as stock cultures. Starter cultures for fermentation were prepared by transferring $5 \%(\mathrm{v} / \mathrm{v})$ of thawed stock cultures into fresh MRS broth and incubating at $37{ }^{\circ} \mathrm{C}$ for $24 \mathrm{~h}$. After two consecutive transfers of the microbial cultures, centrifuging at $8000 \mathrm{~g}$ for $10 \mathrm{~min}$ at $4{ }^{\circ} \mathrm{C}$ was carried out to harvest cells, followed by washing cell pellets twice with physiological saline $\left(8.5 \mathrm{~g} \mathrm{~L}^{-1} \mathrm{NaCl}\right)$. Then, washed cells were resuspended in fresh saline with a similar volume prior to inoculation into fermentation media (17).

\section{Fermentation in presence of lipase (Palatase)}

Briefly, UF whey permeate solution and traditional whey were used as fermentation media. The two media were inoculated with the prepared lactobacilli inocula at $1 \%(\mathrm{v} / \mathrm{v})$ as mono-cultures. Inoculated media were dispensed in $30 \mathrm{~mL}$ aliquots in $50-\mathrm{mL}$ polypropylene tubes and incubated at $30^{\circ} \mathrm{C}$ for $48 \mathrm{~h}$. Lipase (undiluted and filter sterilized) was added into inoculated tubes at $0.1 \%(\mathrm{v} / \mathrm{v})$ concentrations after $24 \mathrm{~h}$ of incubation. Sampling from the tubes was carried out at 0,24 , and $48 \mathrm{~h}$ time intervals to enumerate microbial cells and measure $\mathrm{pH}$ of the samples. 
Inoculated media with no added Palatase and uninoculated media with $0.1 \%$ Palatase served as controls. Appropriate Palatase concentration as well as fermentation duration time were reported based on preliminary experiences. Enumeration of viable cells was carried out as duplicate using MRS agar plates. Inoculated MRS agars were incubated at $37^{\circ} \mathrm{C}$ until colonies grew $(24-48 \mathrm{~h})$. The $\mathrm{pH}$ measurement was carried out using calibrated $\mathrm{pH}$ meter (GLP 22, Crison, Barcelona, Spain).

\section{Ester and free fatty acid analyses by gas chromatography/mass spectrometry}

Fermented and control samples of $48 \mathrm{~h}$ fermentation as well as media with no fermentation and Palatase addition were analyzed for even-numbered free fatty acids (FFA) (up to 12 carbon chain) and their ethyl esters. Samples were prepared by addition of $3 \mathrm{~mL}$ of hexane to $5 \mathrm{~mL}$ of sample and vortexing to extract esters and FAs into hexane phase. Gas chromatograph (HP 6890N, Hewlett Packard, Palo Alto, CA, USA) equipped with DB-225ms capillary column (30 m length, $250 \mu \mathrm{m}$ i.d., $0.25 \mu \mathrm{m}$ film thickness) (Agilent Technologies, Wilmington, DE, USA) was used. Helium with a flow rate of $24 \mathrm{~mL} \mathrm{~min}{ }^{-1}$ was used as carrier gas and Agilent 5973N Inert Mass Selective Detector (MSD) was used for detection. The MS detector was operated in electron ionization mode $(70 \mathrm{eV})$ with ion source temperature of $230{ }^{\circ} \mathrm{C}$. The temperature was held at $50{ }^{\circ} \mathrm{C}$ for $1 \mathrm{~min}$, followed by an increase to $220^{\circ} \mathrm{C}$ by $5{ }^{\circ} \mathrm{C}$ $\mathrm{min}^{-1}$, holding at this temperature for $5 \mathrm{~min}$. Samples were injected in 1- $\mu \mathrm{L}$ volumes at a split ratio of $1: 20$ at $280{ }^{\circ} \mathrm{C}$. Esters and FFAs were identified based on the US National Institute of Standards and Technology and Wiley Libraries databases. Verification of the identified compounds was carried out by the comparison of their retention times with those of C9-C17 saturated alkane standards.

\section{Statistical analysis}

Data were reported as mean values \pm SD (standard deviation) of three independent experiments $(n=3)$. Oneway analysis of variance (ANOVA), Duncan's multiple range test and SPSS Software v.16.0 (IBM Analytics, USA) were used to show significant differences at $p<0.05$.

\section{Results}

\section{Fermentation in presence of lipase (Palatase)}

Table 1 demonstrates effects of Palatase addition on the viable cell counts of three Lactobacillus cultures during a 48-h fermentation period in UF whey permeate and traditional whey. Table 2 displays respective $\mathrm{pH}$ values of the corresponding samples. Accordingly, samples with similar Lactobacillus cultures included similar viable cell counts and $\mathrm{pH}$ values at the beginning of fermentation. Furthermore, each microbial culture included similar cell counts and $\mathrm{pH}$ values during fermentation before the Palatase addition $(0$ and $24 \mathrm{~h})$. This was expected as lactobacilli were inoculated in similar quantities into the samples. Based on Table 1, addition of Palatase to fermentation media at Hour 24 did not significantly affect the growth rate and final viable cell counts of $L$. reuteri and L. buchneri. However, increases of 0.51 and $0.65 \mathrm{log}$ $\mathrm{CFU} / \mathrm{mL}$ were seen in viable cell counts of $L$. fermentum after Palatase addition to UF whey permeate and traditional whey, respectively. After $48 \mathrm{~h}$ of fermentation, no significant differences were seen in the viable cell count of each Lactobacillus between the UF whey permeate and the traditional whey. Based on Table 2, L. reuteri did not show significant differences in $\mathrm{pH}$ values between the control and Palatase treated samples. For L. buchneri and $L$. fermentum, $\mathrm{pH}$ decreased in UF whey permeate samples after $48 \mathrm{~h}$; however, $\mathrm{pH}$ did not change in traditional whey samples.

Table 1. Changes in microbial counts ( $\log \mathrm{CFU} / \mathrm{mL})$ during 48 -h fermentation of traditional whey and UF whey permeate by Lactobacillus species using Palatase

\begin{tabular}{|c|c|c|c|c|c|c|c|}
\hline \multirow[t]{2}{*}{ Fermentation medium } & \multirow[t]{2}{*}{ Time (h) } & \multicolumn{3}{|c|}{ With Palatase } & \multicolumn{3}{|c|}{ Without Palatase } \\
\hline & & $\begin{array}{l}\text { Lactobacillus } \\
\text { fermentum }\end{array}$ & $\begin{array}{c}\text { Lactobacillus } \\
\text { buchneri }\end{array}$ & $\begin{array}{c}\text { Lactobacillus } \\
\text { reuteri }\end{array}$ & $\begin{array}{l}\text { Lactobacillus } \\
\text { fermentum }\end{array}$ & $\begin{array}{c}\text { Lactobacillus } \\
\text { buchneri }\end{array}$ & $\begin{array}{c}\text { Lactobacillus } \\
\text { reuteri }\end{array}$ \\
\hline \multirow[t]{3}{*}{ UF whey permeate } & 0 & $7.05 \pm 0.12^{\mathrm{a} *}$ & $7.17 \pm 0.11^{\mathrm{a}}$ & $7.17 \pm 0.11^{\mathrm{a}}$ & $7.01 \pm 0.16^{\mathrm{a}}$ & $7.17 \pm 0.11^{\mathrm{a}}$ & $7.13 \pm 0.13^{\mathrm{a}}$ \\
\hline & 24 & $7.48 \pm 0.07^{\mathrm{b}}$ & $7.22 \pm 0.01^{\mathrm{a}}$ & $8.18 \pm 0.06^{\mathrm{b}}$ & $7.55 \pm 0.11^{\mathrm{b}, \mathrm{c}}$ & $7.09 \pm 0.12^{\mathrm{a}}$ & $8.14 \pm 0.06^{\mathrm{b}}$ \\
\hline & 48 & $8.22 \pm 0.07^{\mathrm{d}}$ & $8.12 \pm 0.08^{b}$ & $8.42 \pm 0.05^{\mathrm{c}, \mathrm{d}}$ & $7.71 \pm 0.27^{\mathrm{b}, \mathrm{c}}$ & $8.25 \pm 0.02^{\mathrm{b}}$ & $8.47 \pm 0.09^{\mathrm{d}}$ \\
\hline \multirow[t]{3}{*}{ Traditional whey } & 0 & $7.05 \pm 0.11^{\mathrm{a}}$ & $7.20 \pm 0.15^{\mathrm{a}}$ & $7.14 \pm 0.18^{\mathrm{a}}$ & $7.07 \pm 0.11^{\mathrm{a}}$ & $7.20 \pm 0.17^{\mathrm{a}}$ & $7.15 \pm 0.15^{\mathrm{a}}$ \\
\hline & 24 & $7.74 \pm 0.05^{\mathrm{c}}$ & $7.11 \pm 0.13^{\mathrm{a}}$ & $8.27 \pm 0.14^{\mathrm{b}, \mathrm{c}}$ & $7.73 \pm 0.02^{b, c}$ & $7.20 \pm 0.05^{\mathrm{a}}$ & $8.26 \pm 0.07^{b, c}$ \\
\hline & 48 & $8.29 \pm 0.17^{\mathrm{d}}$ & $8.11 \pm 0.20^{\mathrm{b}}$ & $8.47 \pm 0.13^{\mathrm{d}}$ & $7.64 \pm .032^{b, c}$ & $8.10 \pm 0.22^{b}$ & $8.47 \pm 0.16^{\mathrm{d}}$ \\
\hline
\end{tabular}

* Each microorganism analyzed separately. Values are expressed as the mean \pm SD of three independent experiments $(n=3)$. Mean values in the columns of each microorganism (with and without Palatase) with different lowercase letters are significantly different $(P<0.05)$. 
Table 2. Changes in $\mathrm{pH}$ values during 48-h fermentation of traditional whey and UF whey permeate by Lactobacillus species using Palatase

\begin{tabular}{lcccccccc}
\hline Fermentation medium & Time (h) & \multicolumn{3}{c}{ With Palatase } & & \multicolumn{3}{c}{ Without Palatase } \\
\cline { 3 - 4 } & & $\begin{array}{c}\text { Lactobacillus } \\
\text { fermentum }\end{array}$ & $\begin{array}{c}\text { Lactobacillus } \\
\text { buchneri }\end{array}$ & $\begin{array}{c}\text { Lactobacillus } \\
\text { reuteri }\end{array}$ & $\begin{array}{c}\text { Lactobacillus } \\
\text { fermentum }\end{array}$ & $\begin{array}{c}\text { Lactobacillus } \\
\text { buchneri }\end{array}$ & $\begin{array}{c}\text { Lactobacillus } \\
\text { reuteri }\end{array}$ \\
\hline UF whey permeate & 0 & $6.46 \pm 0.16^{\mathrm{d} *}$ & $6.45 \pm 0.12^{\mathrm{c}}$ & $6.42 \pm 0.13^{\mathrm{c}}$ & & $6.46 \pm 0.15^{\mathrm{d}}$ & $6.44 \pm 0.15^{\mathrm{c}}$ & $6.42 \pm 0.16^{\mathrm{c}}$ \\
& 24 & $5.76 \pm 0.40^{\mathrm{c}}$ & $6.31 \pm 0.16^{\mathrm{c}}$ & $5.67 \pm 0.37^{\mathrm{b}}$ & & $5.78 \pm 0.34^{\mathrm{c}}$ & $6.27 \pm 0.21^{\mathrm{c}}$ & $5.76 \pm 0.29^{\mathrm{b}}$ \\
& 48 & $4.57 \pm 0.06^{\mathrm{a}}$ & $4.99 \pm 0.26^{\mathrm{a}}$ & $4.02 \pm 0.34^{\mathrm{a}}$ & & $5.12 \pm 0.35^{\mathrm{b}}$ & $5.27 \pm 0.15^{\mathrm{b}}$ & $4.51 \pm 0.32^{\mathrm{a}}$ \\
Traditional whey & 0 & $6.43 \pm 0.21^{\mathrm{d}}$ & $6.40 \pm 0.19^{\mathrm{c}}$ & $6.42 \pm 0.21^{\mathrm{c}}$ & & $6.42 \pm 0.21^{\mathrm{d}}$ & $6.38 \pm 0.19^{\mathrm{c}}$ & $6.39 \pm 0.23^{\mathrm{c}}$ \\
& 24 & $5.73 \pm 0.34^{\mathrm{c}}$ & $6.26 \pm 0.27^{\mathrm{c}}$ & $5.56 \pm 0.33^{\mathrm{b}}$ & & $5.76 \pm 0.27^{\mathrm{c}}$ & $6.35 \pm 0.03^{\mathrm{c}}$ & $5.54 \pm 0.30^{\mathrm{b}}$ \\
& 48 & $4.73 \pm 0.15^{\mathrm{a}, \mathrm{b}}$ & $5.32 \pm 0.01^{\mathrm{b}}$ & $4.06 \pm 0.38^{\mathrm{a}}$ & & $5.02 \pm 0.33^{\mathrm{a}, \mathrm{b}}$ & $5.33 \pm 0.25^{\mathrm{b}}$ & $4.44 \pm 0.41^{\mathrm{a}}$ \\
\hline
\end{tabular}

* Each microorganism analyzed separately. Values are expressed as the mean \pm SD of three independent experiments $(n=3)$. Mean values in the columns of each microorganism (with and without Palatase) with different lowercase letters are significantly different $(P<0.05)$.

\section{Ester and free fatty acid analyses using gas chromatography/mass spectrometry}

In this study, ethyl esters of SCFAs (up to 12 carbon chains) were assessed. Results from Table 3 show the peak areas $\left(\times 10^{5}\right)$ of FA ethyl esters from UF whey permeate and traditional whey after $48 \mathrm{~h}$ of fermentation with and without Palatase addition. No esters were detected in samples with no bacteria and Palatase. As shown in Table 3 , ethyl acetate was the only ethyl ester detected in fermented samples with no Palatase. The $L$. reuteri with no Palatase addition produced no esters in UF whey permeate and traditional whey. Palatase addition significantly increased levels of all ethyl esters in all samples and samples containing esters smelled fruity. Based on Table 3, L. buchneri produced the lowest levels of esters in the two fermentation media, compared to that L. fermentum and $L$. reuteri did. In most cases, ester levels produced by $L$. reuteri were significantly higher than those produced by $L$. fermentum. However, L. fermentum was a more efficient ethyl acetate producer, especially in UF whey permeate media with a high peak area $\left(\times 10^{5}\right)$ of 103.55 . Despite $L$. fermentum with a higher ester level production in UF whey permeate, two other lactobacilli produced higher ester levels in traditional whey. Based on Table 4, decanoic and dodecanoic acids were detected with no significant differences in their levels in samples with no Palatase addition. Shorter chain free fatty acids (SCFFA) were not detected in these samples. However, Palatase addition increased FFAs in all treated samples. The L. buchneri samples containing Palatase included higher FFA levels than $L$. reuteri and L. fermentum samples in the two media. The $L$. reuteri samples included the lowest FFAs between the three lactobacilli strains. Palatase treated traditional whey samples fermented by L. fermentum included high FFA levels. Overall, FFA levels were higher in traditional whey rather than UF whey permeate.

Table 3. Ester levels (peak area $\times 10^{5}$ ) of the samples after $48 \mathrm{~h}$ of fermentation by Lactobacillus species using Palatase

\begin{tabular}{|c|c|c|c|c|c|c|c|}
\hline \multirow{2}{*}{$\begin{array}{l}\text { Fermentation medium \& Palatase } \\
\text { addition }\end{array}$} & \multirow[t]{2}{*}{ Microorganism } & \multicolumn{6}{|c|}{ Ethyl esters } \\
\hline & & Ethyl acetate & Ethyl butanoate & $\begin{array}{c}\text { Ethyl } \\
\text { hexanoate }\end{array}$ & $\begin{array}{c}\text { Ethyl } \\
\text { octanoate }\end{array}$ & $\begin{array}{c}\text { Ethyl } \\
\text { decanoate }\end{array}$ & $\begin{array}{c}\text { Ethyl } \\
\text { dodecanoate }\end{array}$ \\
\hline \multirow[t]{3}{*}{ UF whey permeate with Palatase } & Lactobacillus fermentum & $103.55 \pm 27.33^{\mathrm{e}_{*}}$ & $23.60 \pm 4.28^{\mathrm{d}}$ & $26.30 \pm 5.98^{\mathrm{d}}$ & $8.73 \pm 3.13^{\mathrm{c}}$ & $21.04 \pm 6.04^{\mathrm{c}}$ & $18.36 \pm 4.39^{\mathrm{d}}$ \\
\hline & Lactobacillus buchneri & $11.16 \pm 2.91^{\mathrm{c}, \mathrm{d}}$ & $2.11 \pm 0.78^{\mathrm{a}}$ & $1.47 \pm 0.72^{\mathrm{a}}$ & $\mathrm{nd}^{* *}$ & nd & $2.52 \pm 0.60^{\mathrm{a}}$ \\
\hline & Lactobacillus reuteri & $7.81 \pm 2.20^{\mathrm{b}}$ & $24.07 \pm 6.21^{\mathrm{d}}$ & $28.96 \pm 7.85^{\mathrm{e}}$ & $8.35 \pm 2.55^{\mathrm{b}, \mathrm{c}}$ & $23.49 \pm 5.81^{\mathrm{d}}$ & $23.53 \pm 7.78^{\mathrm{e}}$ \\
\hline \multirow[t]{3}{*}{ UF whey permeate without Palatase } & Lactobacillus fermentum & $5.34 \pm 1.36^{\mathrm{a}, \mathrm{b}}$ & nd & nd & nd & nd & nd \\
\hline & Lactobacillus buchneri & $5.18 \pm 1.83^{\mathrm{a}, \mathrm{b}}$ & nd & nd & nd & nd & nd \\
\hline & Lactobacillus reuteri & nd & nd & nd & nd & nd & nd \\
\hline \multirow[t]{3}{*}{ Traditional whey with Palatase } & Lactobacillus fermentum & $12.29 \pm 3.33^{\mathrm{d}}$ & $18.84 \pm 5.11^{\mathrm{c}}$ & $20.64 \pm 7.34^{\mathrm{c}}$ & $7.53 \pm 1.81^{\mathrm{b}}$ & $18.16 \pm 4.14^{\mathrm{b}}$ & $14.66 \pm 4.05^{\mathrm{c}}$ \\
\hline & Lactobacillus buchneri & $8.40 \pm 2.03^{\mathrm{b}, \mathrm{c}}$ & $8.16 \pm 2.19^{\mathrm{b}}$ & $8.18 \pm 2.70^{\mathrm{b}}$ & $2.63 \pm 0.55^{\mathrm{a}}$ & $5.73 \pm 1.59^{\mathrm{a}}$ & $5.28 \pm 2.21^{\mathrm{b}}$ \\
\hline & Lactobacillus reuteri & $6.19 \pm 1.78^{\mathrm{a}, \mathrm{b}}$ & $26.22 \pm 7.63^{\mathrm{e}}$ & $42.00 \pm 11.87^{\mathrm{f}}$ & $16.97 \pm 3.08^{\mathrm{d}}$ & $38.87 \pm 10.03^{\mathrm{e}}$ & $36.75 \pm 11.38^{\mathrm{f}}$ \\
\hline \multirow[t]{3}{*}{ Traditional whey without Palatase } & Lactobacillus fermentum & $4.37 \pm 0.98^{\mathrm{a}}$ & nd & nd & nd & nd & nd \\
\hline & Lactobacillus buchneri & nd & nd & nd & nd & nd & nd \\
\hline & Lactobacillus reuteri & nd & nd & nd & nd & nd & nd \\
\hline
\end{tabular}

* Each ester analyzed separately. Values are expressed as the mean \pm SD of three independent experiments $(n=3)$. Mean values in the same column with different lowercase letters are significantly different $(P<0.05)$.

** Not detected 
Table 4. Free fatty acid production (peak area $\times 10^{5}$ ) in samples after $48 \mathrm{~h}$ of fermentation by Lactobacillus species using Palatase

\begin{tabular}{|c|c|c|c|c|c|c|c|}
\hline \multirow{2}{*}{$\begin{array}{l}\text { Fermentation medium \& Palatase } \\
\text { addition }\end{array}$} & \multirow[t]{2}{*}{ Microorganism } & \multicolumn{6}{|c|}{ Fatty acids } \\
\hline & & Acetic acid & Butanoic acid & Hexanoic acid & Octanoic acid & Decanoic acid & Dodecanoic acid \\
\hline \multirow[t]{3}{*}{ UF whey permeate with Palatase } & Lactobacillus fermentum & $1.09 \pm 0.33^{\mathrm{a} *}$ & $16.91 \pm 4.98^{\mathrm{a}}$ & $48.19 \pm 12.81^{\mathrm{c}}$ & $38.27 \pm 9.54^{\mathrm{d}}$ & $69.46 \pm 21.79^{d}$ & $66.36 \pm 20.63^{\mathrm{e}}$ \\
\hline & Lactobacillus buchneri & $\mathrm{nd}^{* *}$ & $21.70 \pm 5.51^{\mathrm{b}}$ & $64.38 \pm 13.19^{\mathrm{d}}$ & $47.50 \pm 13.80^{\mathrm{e}}$ & $90.00 \pm 21.43^{\mathrm{e}}$ & $72.53 \pm 22.58^{\mathrm{f}}$ \\
\hline & Lactobacillus reuteri & $1.67 \pm 0.81^{b}$ & $16.09 \pm 3.97^{\mathrm{a}}$ & $34.88 \pm 9.58^{\mathrm{a}}$ & $28.44 \pm 6.59^{\mathrm{b}}$ & $42.71 \pm 12.82^{b}$ & $26.78 \pm 10.54^{\mathrm{b}}$ \\
\hline \multirow[t]{3}{*}{ UF whey permeate without Palatase } & Lactobacillus fermentum & nd & nd & nd & $2.55 \pm 0.79^{\mathrm{a}}$ & $4.47 \pm 1.52^{\mathrm{a}}$ & $3.79 \pm 1.16^{\mathrm{a}}$ \\
\hline & Lactobacillus buchneri & nd & nd & nd & nd & $2.69 \pm 0.66^{\mathrm{a}}$ & $5.05 \pm 2.01^{\mathrm{a}}$ \\
\hline & Lactobacillus reuteri & nd & nd & nd & nd & $3.88 \pm 1.35^{\mathrm{a}}$ & $1.61 \pm 0.71^{\mathrm{a}}$ \\
\hline \multirow[t]{3}{*}{ Traditional whey with Palatase } & Lactobacillus fermentum & nd & $21.50 \pm 6.86^{b}$ & $68.91 \pm 17.07^{\mathrm{d}, \mathrm{e}}$ & $48.59 \pm 13.13^{\mathrm{e}}$ & $95.72 \pm 27.25^{\mathrm{f}}$ & $79.64 \pm 21.62^{\mathrm{g}}$ \\
\hline & Lactobacillus buchneri & nd & $21.80 \pm 7.13^{\mathrm{b}}$ & $72.47 \pm 13.56^{\mathrm{e}}$ & $50.36 \pm 18.21^{\mathrm{e}}$ & $90.63 \pm 26.90^{\mathrm{e}}$ & $61.23 \pm 18.57^{\mathrm{d}}$ \\
\hline & Lactobacillus reuteri & $2.42 \pm 1.11^{\mathrm{c}}$ & $20.94 \pm 5.35^{\mathrm{b}}$ & $40.01 \pm 11.61^{\mathrm{b}}$ & $32.65 \pm 8.05^{\mathrm{c}}$ & $55.35 \pm 16.65^{\mathrm{c}}$ & $38.11 \pm 10.58^{\mathrm{c}}$ \\
\hline \multirow[t]{3}{*}{ Traditional whey without Palatase } & Lactobacillus fermentum & nd & nd & nd & nd & $2.75 \pm 1.63^{\mathrm{a}}$ & $1.18 \pm 0.34^{\mathrm{a}}$ \\
\hline & Lactobacillus buchneri & nd & nd & nd & nd & $3.38 \pm 1.56^{\mathrm{a}}$ & $2.91 \pm 0.95^{\mathrm{a}}$ \\
\hline & Lactobacillus reuteri & nd & nd & nd & nd & $0.99 \pm 0.14^{\mathrm{a}}$ & $1.80 \pm 0.66^{\mathrm{a}}$ \\
\hline
\end{tabular}

* Each fatty acid analyzed separately. Values are expressed as the mean \pm SD of three independent experiments $(n=3)$. Mean values in the same column with different lowercase letters are significantly different $(P<0.05)$.

** Not detected

\section{Discussion}

Based on the obtained results, increased viable cell counts of Palatase-treated L. fermentum samples was unexpected since the MCFAs released from fats due to hydrolytic activities of Palatase could include antibacterial effects (18). However, FFAs could not inhibit the growth rate of the selected lactobacilli in the current study. In a previous study by Sun et al. on Saccharomyces cerevisiae fermentation in coconut creams, yeast counts decreased after Palatase addition (9). This difference could be due to different stress tolerance levels of yeast and lactobacilli cells. Teichoic acid of the bacterial cell walls has been reported to protect bacteria against FFAs (19). The hydrolytic activity of Palatase was the reason of $\mathrm{pH}$ decrease in Palatase treated samples. It seemed that Palatase did not significantly decrease $\mathrm{pH}$ values in most of the samples, especially in traditional whey. This could be a result of esterification/transesterification reactions of Palatase, which decreased the FFA content of the media. Quantities of the esters produced by Palatase could be affected by the ethanol content produced during fermentation as well as viable cell counts of the ethanol producing microbial cultures and $\mathrm{pH}$ of the fermentation media. The working $\mathrm{pH}$ range of Palatase is naturally 5.09.5 with optimum of 6.5-7.5 (20). The viable cell count of L. buchneri was not lower than those of other Lactobacillus cultures within $48 \mathrm{~h}$. The $\mathrm{pH}$ values of the samples fermented by L. buchneri were $\geq 5$, which favored Palatase activity. Hence, lower ability of ethanol production was likely the reason of lower ester levels produced by $L$. buchneri. Ethyl acetate detected in fermented samples with no Palatase was not produced by the Palatase activity but produced by fermentation $(21,22)$. Based on the cell counts and $\mathrm{pH}$ values, ethanol contents of the media could be the major cause of higher ester productions in L. reuteri samples, compared to L. fermentum samples.

In UF whey permeate fermented by L. fermentum, factors other than esterification reactions seemed to be effective in ethyl acetate production. One possibility could be the released components due to hydrolytic activity of Palatase, which promoted ethyl acetate production by the bacteria. Lactic acid (LA) produced by lactobacilli species during fermentation (23) was expected to be esterified with ethanol in presence of Palatase. Nevertheless, ethyl lactate was not detected in the current study. This was most possibly due to lipase type and ability of Palatase in esterifying ethanol and LA. Ethanol and LA are naturally hydrophilic compounds, which prefer to set in the aqueous phase rather than the oil-water interface. This causes difficulties in direct esterification of the chemicals for Palatase (24). However, Palatase in its immobilized form could synthesize ethyl lactate in a previous study (25). In a study by Liu et al., Palatase could not directly esterify butanoic acid and ethanol whereas alcoholysis of tributyrin with ethanol was a better choice to synthesize ethyl butanoate by this lipase. This was due to the higher hydrophobicity of tributyrin (8). In fact, alcohol to acid ratio is an important factor in esterification reactions (26, 27). In the present study, ethanol level was not possibly sufficient for the esterification of LA because ethanol was gradually used by Palatase, while LA increased due to fermentation. 
Hydrophobic nature of the fermentation media is another effective factor in Palatase activity. Previously, Sun and Liu compared the mechanism of ester synthesis in coconut creams and buffer systems and revealed that the coconut cream media were further appropriate due to their higher hydrophobicity (24). Therefore, fat content added to whey could directly affect the produced ester levels. Other substances in the media could affect distribution of water between lipase and reaction media, affecting lipase activity as a result (24). Moreover, Palatase addition increased FFA levels due to its hydrolytic activity. The higher FFA levels of L. buchneri samples with Palatase addition were linked to its lower capacity in ethanol production, which caused non-esterified FFAs. In contrast, lower FFA levels could be due to higher esterification reactions in $L$. reuteri samples. In a previous study on coconut creams, it was reported that synthetic activity of Palatase was affected by $\mathrm{pH}$ whereas its hydrolytic activity was not affected (9). In the current study, the lower $\mathrm{pH}$ values of $L$. reuteri samples were not likely the reasons for low FA levels. Decanoic and dodecanoic acids in samples with no Palatase showed that these FAs were either products of fermentation (28) or releases from the fats of media by microbial esterases and lipases (29). Limitations of the GC method or low concentrations of SCFAs possibly caused them to be undetectable in samples with no Palatase (30). Totally, FFA levels were higher in traditional whey than UF whey permeate. One hypothesis includes various compositions of the two media with stimulatory or inhibitory effects on Palatase activity. It has been reported that various cations can stimulate or inhibit lipases (31). Inhibitory effects of immunoglobulins on lipases have been reported (32). However, fat contents and overall $\mathrm{pH}$ levels of the two media were similar and hence cannot be acceptable reasons. Despite smelling fruity and having potential to be consumed directly as a beverage with natural fruity flavorings, further studies are needed to improve tastes of the products. Low fat dairies can benefit these products in their formulations to improve their tastes (10). Esters include capabilities to mask goat-like and mutton-like flavors in dairy products (6).

\section{Conclusion}

This study was carried out to assess in situ fruity flavor biosynthesis in whey and UF whey permeate using lipase of Palatase with Lactobacillus fermentation. Overall, Palatase did not affect the growth rate of Lactobacillus cultures (except L. fermentum) with increase in viable cell counts of UF whey permeate and traditional whey media. No differences were reported in viable cell counts of Lactobacillus cultures between the UF whey permeate and traditional whey. Palatase decreased $\mathrm{pH}$ values of the fermented samples. Furthermore, Palatase addition increased ethyl ester levels of all the treated samples, generating fruity flavors. The $L$. reuteri was the most efficient ester producer while the lowest ester levels detected in L. buchneri samples. This is a novel method with advantages of using no synthetic flavorings as well as labeling products as natural. Products include potential to be consumed directly or as flavorings in food formulations. Although ethanol was the only alcohol used in this study, further studies can benefit the microorganisms to produce other alcohols to synthetize various esters. Addition of amino acids to fermentation media can be used to achieve this goal.

\section{Financial disclosure}

The authors declare no financial interests.

\section{Acknowledgement}

The authors appreciate helps from the Department of Food Science and Technology, Shiraz University. The authors are also grateful for the financial supports from the Shiraz University.

\section{References}

1. Jun M, Jeong W, Ho C. Health promoting properties of natural flavor substances. Food Sci Biotechnol 2006; 15(3): 329-338.

2. Abdulmumeen HA, Risikat AN, Sururah AR. Food: Its preservatives, additives and applications. Int J Chem Biomol Sci 2012; 1: 36-47.

3. Longo MA, Sanromán MA. Production of food aroma compounds: microbial and enzymatic methodologies. Food Technol Biotechnol 2006; 44(3): 335-53.

4. Vandamme EJ, Soetaert W. Bioflavours and fragrances via fermentation and biocatalysis. J Chem Technol Biotechnol 2002; 77(12): 1323-32.

5. Schwab W, Davidovich-Rikanati R, Lewinsohn E. Biosynthesis of plant-derived flavor compounds. Plant J 2008; 54(4): 712-32.

6. Liu SQ, Holland R, Crow VL. Esters and their biosynthesis in fermented dairy products: a review. Int Dairy J 2004; 14(11): 923-45.

7. Liu SQ, Lee HY, Yu B, Curran P, Sun J. Bioproduction of natural isoamyl esters from coconut cream as catalysed by lipases. J Food Res 2013; 2(2):157.

8. Liu SQ, Holland R, Crow V. Synthesis of ethyl butanoate by a commercial lipase in aqueous media under conditions relevant to cheese ripening. J Dairy Res 2003; 70(3): 359-63.

9. Sun J, Lim Y, Liu SQ. Biosynthesis of flavor esters in coconut cream through coupling fermentation and lipasecatalyzed biocatalysis. Eur J Lipid Sci Technol 2013; 115(10): 1107-14.

10. Zhang XM, Ai NS, Wang J, Tong LJ, Zheng FP, Sun BG. Lipase-catalyzed modification of the flavor profiles in recombined skim milk products by enriching the volatile components. J Dairy Sci 2016; 99(11): 8665-79.

11. Liu SQ, Crow VL, Holland R. Production of natural fruity flavour in dairy foods. Nutr Food Sci 2009; 39: 483-9. 
12. Jafari SM, Masoudi S, Bahrami A. A Taguchi approach production of spray-dried whey powder enriched with nanoencapsulated vitamin D3. Dry Technol 2019; 37(16): 2059-71.

13. Amaro TM, Rosa D, Comi G, Iacumin L. Prospects for the use of whey for polyhydroxyalkanoate (PHA) production. Front Microbiol 2019; 10: 992.

14. Pedersen TB, Ristagno D, McSweeney PL, Vogensen FK, Ardö Y. Potential impact on cheese flavour of heterofermentative bacteria from starter cultures. Int Dairy $\mathbf{J}$ 2013; 33(2): 112-9.

15. Pedersen TB, Vogensen FK, Ardö Y. Effect of heterofermentative lactic acid bacteria of DL-starters in initial ripening of semi-hard cheese. Int Dairy J 2016; 57: 729.

16. Widyastuti Y, Febrisiantosa A. The role of lactic acid bacteria in milk fermentation. FNS 2014; 5(4): 720-726.

17. Toh M, Liu SQ. Impact of coculturing Bifidobacterium animalis subsp. lactis $\mathrm{HN} 019$ with yeasts on microbial viability and metabolite formation. J appl microbiol 2017; 123(4): 956-68

18. Desbois AP, Smith VJ. Antibacterial free fatty acids: activities, mechanisms of action and biotechnological potential. Appl microbiol biotechnol 2010; 85(6): 1629-42.

19. Kohler T, Weidenmaier C, Peschel A. Wall teichoic acid protects Staphylococcus aureus against antimicrobial fatty acids from human skin. J bacteriol 2009; 191(13): 4482-4.

20. Kurtovic I, Marshall SN, Miller MR, Zhao X. Flavour development in dairy cream using fish digestive lipases from Chinook salmon (Oncorhynchus tshawytscha) and New Zealand hoki (Macruronus novaezealandiae). Food Chem 2011; 127(4): 1562-8.

21. Annan NT, Poll L, Sefa-Dedeh S, Plahar WA, Jakobsen M. Volatile compounds produced by Lactobacillus fermentum, Saccharomyces cerevisiae and Candida krusei in single starter culture fermentations of Ghanaian maize dough. J Appl Microbiol 2003; 94(3): 462-74.
22. Quigley L, O'Sullivan O, Stanton C, Beresford TP, Ross RP, Fitzgerald GF, et al. The complex microbiota of raw milk. FEMS Microbiol Rev 2013; 37(5): 664-98.

23. Martinez FA, Balciunas EM, Salgado JM, González JM, Converti A, de Souza Oliveira RP. Lactic acid properties, applications and production: a review. Trends Food Sci Technol 2013; 30(1): 70-83.

24. Sun J, Liu SQ. Ester synthesis in aqueous media by lipase: alcoholysis, esterification and substrate hydrophobicity. J Food Biochem 2015; 39(1): 11-8.

25. Ugur Nigiz F, Durmaz Hilmioglu N. Green solvent synthesis from biomass based source by biocatalytic membrane reactor. Int J Energy Res 2016; 40(1): 71-80.

26. Delgado P, Sanz MT, Beltrán S, Núñez LA. Ethyl lactate production via esterification of lactic acid with ethanol combined with pervaporation. Chem Eng J 2010; 165(2): 693-700.

27. Sun J, Jiang Y, Zhou L, Gao J. Optimization and kinetic study of immobilized lipase-catalyzed synthesis of ethyl lactate. Biocatal Biotransform 2010; 28(4): 279-87.

28. Leclercq-Perlat MN, Corrieu G, Spinnler HE. Controlled production of Camembert-type cheeses: part III role of the ripening microflora on free fatty acid concentrations. $\boldsymbol{J}$ Dairy Res 2007; 74(2): 218-25.

29. Coşkun H, Ondül E. Free fatty acid accumulation by mesophilic lactic acid bacteria in cold-stored milk. J Microbiol 2004; 42(2): 133-8.

30. Holland R, Liu SQ, Crow VL, Delabre ML, Lubbers M, Bennett M, et al. Esterases of lactic acid bacteria and cheese flavour: Milk fat hydrolysis, alcoholysis and esterification. Int Dairy J 2005; 15(6-9): 711-8.

31. Gupta R, Gupta N, Rathi P. Bacterial lipases: an overview of production, purification and biochemical properties. Appl microbiol biotechnol 2004; 64(6): 763-81.

32. Hirose M, Ando T, Shofiqur R, Umeda K, Kodama Y, Van Nguyen S, Goto T, Shimada M, Nagaoka S. Anti-obesity activity of hen egg anti-lipase immunoglobulin yolk, a novel pancreatic lipase inhibitor. Nutr metab 2013; 10(1): 70-5. 